\title{
Development of an Economical High Early Strength Concrete Mix for Paving of Provincial Roads in Sri Lanka
}

\author{
W. K. Mampearachchi, J. V. Kosgolla and S. M. A. Nanayakkara
}

\begin{abstract}
Rigid pavement construction has a long history. Readymixed or site mixed concrete is used for rigid pavement construction. However, conventional concrete mixtures require more than 7 days to gain adequate strength to allow for traffic. Development of high early strength concrete would be a solution to allow traffic within a reasonable time. However, use of high cement content in early strength concrete induces distress in the pavements and would not be an economical mix.
\end{abstract}

A high performance concrete mix was developed for rigid pavement construction using a low cost admixture with available materials in Sri Lanka. Study has shown that 3\% of commercial grade $\mathrm{CaCl}_{2}$ can be used as an accelerator to obtain required compressive strength and the flexural strength of concrete in 12 hours. Strength gain was verified by the maturity test conducted for a slab placed under field condition. Slab temperature was also measured with time and found temperature rise due to heat of hydration was insignificant. Using the mix proportion developed, concrete roads can be allowed for traffic in 12 hours and can also be used for repair works of the existing roads.

Life cycle cost analysis was performed taking into account the construction cost, maintenance cost and the user cost. The study has shown that there is $26 \%$ saving by using high early strength concrete developed in this study.

Keywords: High early strength, Calcium Chloride, Rigid Pavement, Concrete Roads, Life Cycle Cost Analysis

\section{Introduction}

The rigid pavement or Portland Cement Concrete (PCC) pavement should be placed on an improved subgrade or on a subbase of approved type and thickness. The subbase may be natural soil or stabilized soil or graded granular material. Slab thicknesses normally vary between $150 \mathrm{~mm}$ and $300 \mathrm{~mm}$ depending on the subgrade conditions and traffic. Slab width of those roads varies from $3.0 \mathrm{~m}$ to 3.7 $\mathrm{m}$, corresponding to the width of a traffic lane. Once the concrete is placed, suitable poker vibrators or vibrating beams is used for compaction.. The surfaces are finished rough. For this purpose a mechanical broom or suitable hand broom is used. Curing of the laid concrete should be carried out for a minimum period of 7 days.

Joint systems are designed to control cracking and maintain pavement structural integrity and riding quality (road roughness) at low annual cost. Joints in rigid pavements control transverse and longitudinal cracks due to restrained contraction and the combined effects of restrained curling, warping and traffic load.

Further, joints divide the pavement into practical construction increments [10]. Transverse joints are created mainly to accommodate thermal and shrinkage stresses. Concrete Pavements do not necessarily require expansion joints [16].

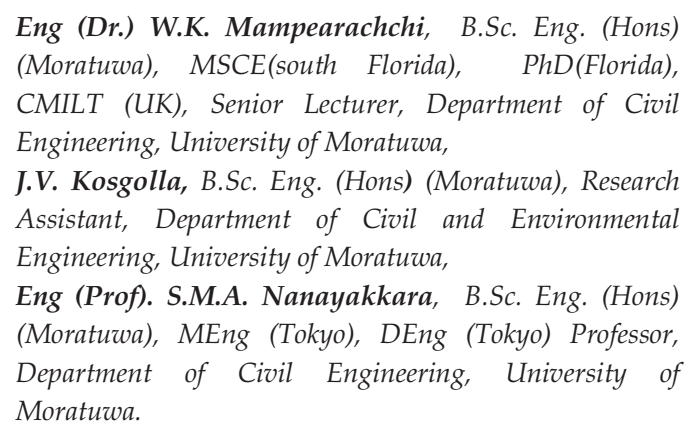


Contraction joints are created by making a saw cut in the slab to a depth of $1 / 3$ of the thickness of the slab [10]. The joints are filled with approved joint filler.

Load transfer at Joints can be further enhanced by using dowel bars across the joints. Dowel bars are usually placed at mid depth of the slab with $300 \mathrm{~mm}$ spacing for thick concrete pavement designed for heavy traffic roads [10]

\section{Research Needs}

Concrete paving has been widely used for low volume roads in Sri Lanka since 2007 with the government allocated funding for local government agencies to construct concrete roads. It is considered as a cost effective road construction technique for low volume roads since concrete roads have less maintenance cost. Currently, few roads managed by the Road Development Authority (RDA), have also been constructed using concrete. Normal concrete needs atleast 28 days to gain sufficient strength to allow for traffic. Therefore, the user cost due to closure of the road for a long period increases the overall cost of the project. There is a need for evaluating life cycle cost considering construction, maintenance and user cost. Increase of concrete early strength to allow traffic at a minimum time should be considered to make concrete paving feasible for roads with considerable traffic.

It has been revealed in field surveys that concrete pavements are allowed to traffic at early age of concrete due to inadequate alternative routes to detour the traffic. Figure 1 shows the vehicle tyre marks of the Middaniya - Weerakettiya road due to such situation.

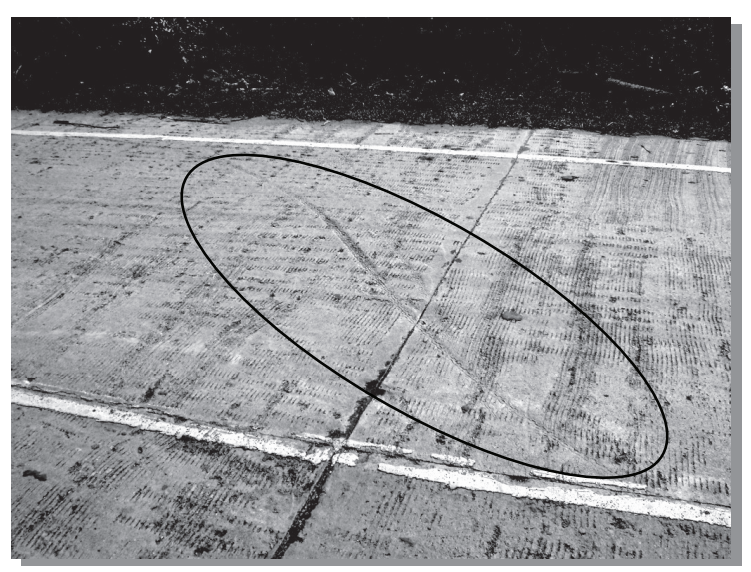

Figure 1- Tire Marks on newly constructed Road, Weerakettiya - Middeniya Road

\section{High Early Strength Concrete Mix for Rigid Pavements}

\section{General requirements}

High early strength concrete should be introduced to reduce the delays and inconvenience to users due to closure of the roads $[1,2,3]$. The required concrete strength is specified in terms of flexural strength or compressive strength or both. Usually, a minimum 28 day flexural strength of 3.9 $\mathrm{N} / \mathrm{mm}^{2}$ (550 psi) or cube crushing strength of $28 \mathrm{~N} / \mathrm{mm}^{2}$ (4000 psi) is recommended by many highway agencies $[11,12]$.

The Florida Department of Transportation (FDOT) specifies that the concrete requires a minimum 6-hour compressive strength of 15.2 $\mathrm{MPa}$ (2200 psi) and a minimum 24 hour compressive strength of $20.7 \mathrm{MPa}$ (3000 psi) before allowing traffic at early age of concrete [7]. The California Department of Transportation specifies a minimum modulus of rupture $2.3 \mathrm{MPa}$ (333 psi) at the time of opening to traffic and $4.3 \mathrm{MPa}(623 \mathrm{psi})$ at 7 days[4]. From a similar study conducted by the authors using heavy vehicle simulator at an accelerated pavement facility, it was found that for a 9-inch slab placed on a strong foundation, a minimum compressive strength of $11 \mathrm{MPa}$ (1600 psi) for the concrete at the time of application of traffic load [12]

Reinforced concrete (0.6-0.7\% of steel) are recommended for continuous concrete slab pavement (joint free) to reduce the crack width. Dowel bars are also recommended for better load transfer between slabs in jointed reinforced concrete pavements. However, Dowel bars can only be installed in concrete pavements with slab thickness of 6 inches or more. The majority of the roads in provincial sector requires maximum of 6 inches thick concrete slabs [8].

Furthermore, American Concrete Pavement Association recommends dowel bar pavement for roads which carry 120 maximum truck traffic per day per lane or maximum Equivalent Standard axle load (ESAL) of 5 million standard axles (msa) or less during design life [16]. In Sri Lanka, only about 600 $\mathrm{km}$ of roads carries the Average Daily Traffic (ADT) of 10,000 or more traffic(Heavey vehicle percentage varies from $3-7 \%$ in provincial roads.[8]) Figure 2 shows the traffic volume of National roads in Sri Lanka. Therefore, it is not 
necessary to use dowel bars in concrete pavements for many national and provincial roads in Sri Lanka. However, closure of these roads for a longer period is not possible because these roads are the primary and secondary links in the road network.

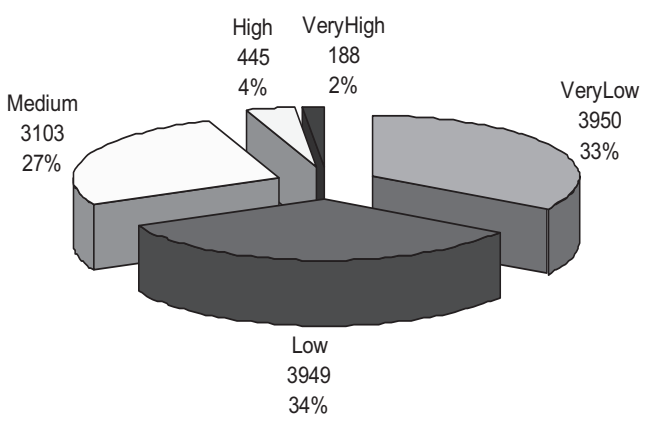

Figure 2 - Road Length distribution by Traffic Volume

Therefore, it is necessary to develop a suitable concrete mix proportion with a suitable admixture available in Sri Lanka to achieve high early strength. $\mathrm{CaCl}_{2}$ was selected as the accelerator to achieve high early strength in concrete.

\section{Calcium Chloride as an admixture}

Several Chemicals are known to act as accelerators for concrete such as Calcium Formate, Aluminium Chloride, Potassium Carbonate, Sodium Chloride and Calcium Chloride [15]. However, Calcium Chloride is the most widely used accelerator in unreinforced concrete. Calcium Chloride $\left(\mathrm{CaCl}_{2}\right)$ is not recommended for reinforced concrete as $\mathrm{CaCl}_{2}$ promotes corrosion of reinforcements. $\mathrm{Cacl}_{2}$ needs to conform to the following requirements to use as an admixture.

Total Alkali Chlorides $\left(\mathrm{Na}^{+} \mathrm{K}^{+}\right)$, max \% 8.0

Total Magnesium as $\mathrm{MgCl}_{2}, \max \% \quad 0.5$

Other impurities, $\max \%$

There are several positive and negative impacts of $\mathrm{CaCl}_{2}$. Calcium Cloride is readily available and also usage of $\mathrm{CaCl}_{2}$ saves enormous cost for construction [17]. It significantly reduces both initial and final setting time of concrete [18]. Apart from that $\mathrm{CaCl}_{2}$ increases the resistance of concrete to erosion and abrasion[18]. However $\mathrm{CaCl}_{2}$ increases drying shrinkage of concrete by 10 $15 \%$ [20]. Because it has a very rapid set. Therefore, even with a slight hot weather conditions, concreting should be avoided. Calcium Chloride does not significantly reduce the water required to produce a given slump. Calcium Chloride does not cause entrainment of air in concrete [18]. It increases heat of hydration of concrete[18].

Calcium chloride is available as pellets or other forms such as granules, flakes, or in solution form. The regular flake form contains a minimum of 77 per cent of calcium chloride and the pellet and other granular forms contain a minimum of 94 per cent. The regular flake form or industrial calcium chloride available in the market is less expensive when compared with the analytical calcium chloride with minimum impurities. The flake form calcium chloride was used in this study to develop more cost effective mix proportion. Calcium chloride is supplied in moisture-proof bags, air-tight drums, or other appropriate means and should be stored carefully against moisture. If any lumps develop during storage they should be discarded. Calcium chloride can be dissolved in either cold or hot water. In preparation of a solution, it is a good practice to add the $\mathrm{CaCl}_{2}$ to the water. If water is added to the $\mathrm{CaCl}_{2}$, hard coating forms and makes dissolution slow. Freshly made solution is turned to be warm and should be cooled to room temperature before use.

High concentrated solutions of calcium chloride are not prepared because of the possibility that excess chloride will settle to the bottom. It is more convenient to prepare a solution containing $0.65 \mathrm{~kg}$ of regular flake form (with 77 percent minimum calcium chloride) or $0.53 \mathrm{~kg}$ of pellet or concentrated flake or other granulated form (with 94 percent minimum calcium chloride) in each liter of solution. It then becomes practical, though not exact, to add 1 liter of standard solution per sack of cement when 1 per cent calcium chloride is specified. The solution is considered to be a part of the mixing water for concrete.

Calcium chloride solution may be added manually, but an automatic dispenser is more reliable. The solution should not come into direct contact with cement because it may flash set. It is usually added to the mixing water or to the aggregates. When calcium chloride solution is supplied directly by the manufacturer, its strength can be assessed by determining the specific gravity with a hydrometer. 


\section{Effect of $\mathrm{CaCl}_{2}$ on Setting of Concrete}

Calcium chloride significantly reduces both initial and final setting time of concrete. This is particularly useful for concreting operations carried out at low or moderate temperatures. Excessive amounts (for example, 4 per cent by the weight of cement) cause a very rapid set. $\mathrm{CaCl}_{2}$ should not be used in hot weather because setting may occur so rapidly that placing and finishing may become very difficult; strength may also be affected. [18].

\section{Concrete mix design}

Strength development of concrete is a critical factor in determining the time of opening of the pavement to traffic. The 28-day strength of the mix should also be considered when designing pavements for long-term effects of fatigue and other traffic-induced distresses.

The mix design was performed to achieve the average 28-day compressive strength of 35 $\mathrm{N} / \mathrm{mm}^{2}$ and slump in the range of $80-100 \mathrm{~mm}$.

By following the DoE mix design procedure [21], a mix proportion was obtained to achieve the required performance with the above parameters as given in Table 1.

Concrete cubes were cast and tested at 4 hours, 6 hours, 8 hours, 12 hours, 24 hours, 7 days and 28 days. Figure 3 shows the strength gain with time for different dosages of $\mathrm{CaCl}_{2}$ based on cement content.

Table 1 - Mix proportion for concrete pavement

\begin{tabular}{|l|c|}
\hline Cement (OPC), $\mathrm{kg} / \mathrm{m}^{3}$ & 417 \\
\hline Fine aggregate, $\mathrm{kg} / \mathrm{m}^{3}$ & 692 \\
\hline Coarse aggregate, $\mathrm{kg} / \mathrm{m}^{3}$ & 1024 \\
\hline Water, $\mathrm{kg} / \mathrm{m}^{3}$ & 200 \\
\hline $\begin{array}{l}\text { CaCl} 2 \text { (measured as a } \\
\text { percentage, } \% \text { of cement } \\
\text { content) }\end{array}$ & $0-4$ \\
\hline
\end{tabular}

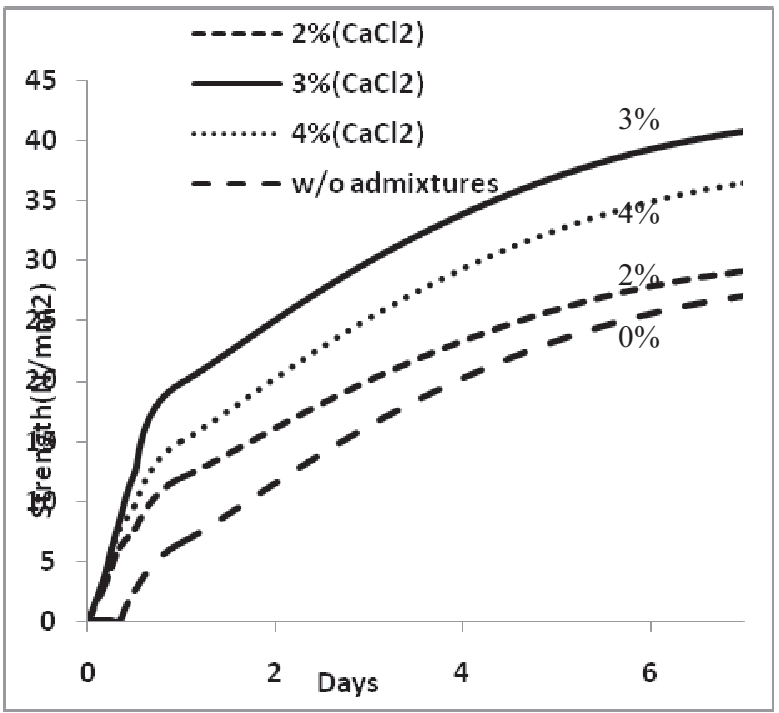

Figure 3 - Compressive strength gain with $\mathrm{CaCl}_{2}$

As shown in Figure 3, highest strength gain was obtained for $3 \%$ of $\mathrm{CaCl}_{2}$ content. That amount can be identified as the optimum amount of $\mathrm{CaCl}_{2}$ for rapid strength gain.

According to a previous study [ 11, 12], the minimum compressive strength of concrete required to allow traffic after placing of concrete is $11 \mathrm{MPa}$ (1600 psi). Based on the above research, the required strength can be obtained in 12 hours with $3 \%$ of $\mathrm{CaCl}_{2}$.

\section{Temperature-time relationship}

Figure 4 shows the temperature variation with time of test cubes $(150 \mathrm{~mm} \times 150 \mathrm{~mm} \times 150$ $\mathrm{mm}$ ) with various $\mathrm{CaCl}_{2}$ percentages. It can be seen that there is a temperature rise in concrete with $\mathrm{CaCl}_{2}$ and it increases with the increase of $\mathrm{CaCl}_{2}$ percentage.

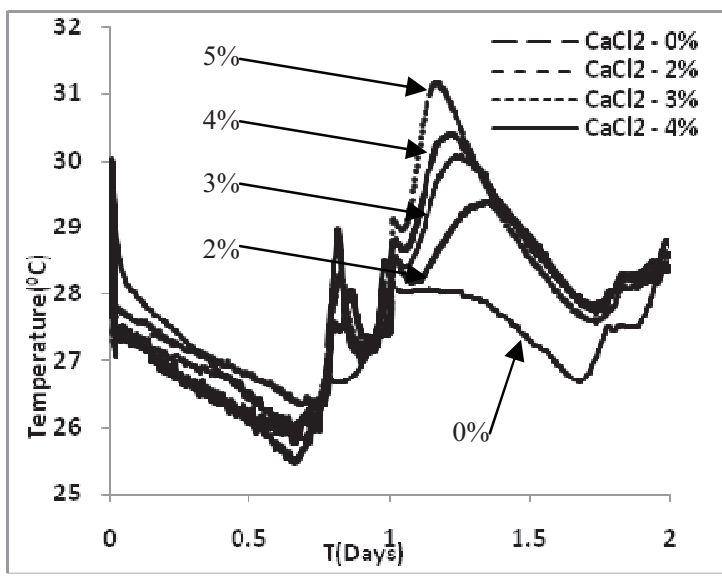

Figure 4 - Temperature-time relationship of test cubes 
Maximum recorded temperature difference with respect to $0 \% \mathrm{CaCl}_{2}$ was $1.5^{\circ} \mathrm{C}$ for $3 \%$ of $\mathrm{CaCl}_{2}$. This early stage temperature development due to $\mathrm{Cacl}_{2}$ can be considered as insignificant for concrete pavements in the range of $150 \mathrm{~mm}$ thick. However, temperature rise should be monitored under field condition to verify this.

\section{Time of placement}

Hot whether concreting should be avoided since the concrete with $\mathrm{Cacl}_{2}$ can set faster and temperature increase may be significant. When concrete is placed under warm sunny conditions, the maximum temperature of the concrete will vary depending upon the time of the day. Concrete paved in early morning will often reach a higher maximum temperature than the concrete paved in late morning and afternoon. It has been found from a previous study that concrete placed in the morning becomes nearly $13^{\circ} \mathrm{C}$ warmer than the concrete placed in late afternoon. [9]. By placing the concrete in evening (preferably after $6 \mathrm{pm}$ ) will reduce the heat generation in the concrete and also less disruption to traffic.

\section{Maturity Test}

The strength of a concrete mixture that has been properly placed and cured can be expressed as a function of the age and temperature history [19]. Increase in curing temperature and longer curing times lead to increase in strength development. Maturity testing provides a reliable technique for continuous monitoring of strength gain of concrete. The test method recognizes the combined effect of time and temperature and provides a basis for estimating the in situ strength gain of concrete by monitoring temperature of concrete over time.

Maturity directly shows a relationship to strength. The maturity of concrete may be defined as its age multiplied by the average temperature that it has maintained. Based on the definition, the law of strength gain with maturity was developed. The law states: concrete of the same mixture at the same maturity (measured as temperature-time) gives approximately the same strength whatever combination of temperature and time goes to make up that maturity [19].

\section{Benefits and limitations}

The maturity approach provides a useful and simple means of estimating the strength gain of concrete at early age (generally less than 14 days old) [5]. It allows engineers to assess the in place strength of a concrete pavement structure. This valuable information can then be used to determine the appropriate time for opening a pavement to traffic, or for sawing joints or for stripping forms. Furthermore, cost of quality assurance decreases and maturity monitoring causes no damage to the existing concrete pavement.

However, calibration curves as shown in Figure 4 are developed based on projectspecific materials. Any changes in the mix design will require a new calibration curve. Also some factors affecting concrete strength, e.g., consolidation may not be considered in maturity testing. Maturity test does not consider the effect of early age concrete temperature on long term ultimate strength [14].

The Nurse-Saul maturity relationship was developed in 1950s and the most widely accepted means of computing maturity is the accumulated product of time and temperature [14]:

$\mathrm{M}=\sum\left(\mathrm{T}_{\mathrm{a}}-\mathrm{T}_{\mathrm{o}}\right) \Delta \mathrm{t}$

Where:

$\mathrm{M}=$ maturity at age $\mathrm{t}$

$\mathrm{T}_{\mathrm{a}}=$ average concrete temperature during time interval $\Delta \mathrm{t}$

$\mathrm{T}_{0}=$ datum temperature

$\Delta \mathrm{t}=$ time interval

The datum temperature is the temperature at which concrete strength gain ceases. Generally a value of $10^{\circ}$ $\mathrm{C}$ is used for the datum temperature in the Nurse-Saul equation.

\section{Test procedure}

Concrete slab of $1.2 \mathrm{~m} \times 1.2 \mathrm{~m} \times 100 \mathrm{~mm}$ was cast to monitor temperature and strength development. The thermocouples were placed at the mid depth of the middle of the slab in order to measure the temperature under field condition. Sixteen (16) test cubes were cast to perform compressive strength test at 4 hours, 6 hours, 8 hours, 12 hours and 24 hours. Thermocouples were embedded in one of the test cubes. Curing was done in accordance with ASTM C31. Compression testing was conducted according to ASTM C78. After that 
the compressive strength and corresponding maturity value (in terms of ${ }^{0} \mathrm{C}$.Hours) were recorded for each age. Table 2 shows maturity test results.

Table 2 - Maturity values

\begin{tabular}{|c|c|c|c|}
\hline \multirow[b]{2}{*}{$\begin{array}{l}\text { Age of } \\
\text { Concrete }\end{array}$} & \multirow{2}{*}{$\begin{array}{l}\text { Compressive } \\
\text { Strength } \\
\text { (laboratory) } \\
\left(\mathrm{N} / \mathrm{mm}^{2}\right)\end{array}$} & \multicolumn{2}{|c|}{ Maturity ( ${ }^{\circ} \mathrm{C}$ - Hours) } \\
\hline & & Laboratory & Field \\
\hline 4 Hours & 2.8 & 169.7 & 170.8 \\
\hline 6 Hours & 5.2 & 256.3 & 269.1 \\
\hline 8 Hours & 7.1 & 339.9 & 360.7 \\
\hline 12 Hours & 11 & 498.7 & 573.3 \\
\hline 24 Hours & 18.3 & 990.5 & 1043 \\
\hline
\end{tabular}

Figure 4 shows the maturity calibration curve for laboratory test results. According to the characteristics of the curve, after 12 hours, the concrete has gained strength of $12 \mathrm{~N} / \mathrm{mm}^{2}$ at a maturity level of $573.3^{\circ} \mathrm{C}$ hours under field condition. Therefore, the pavement can be opened for the traffic less than 12 hours.

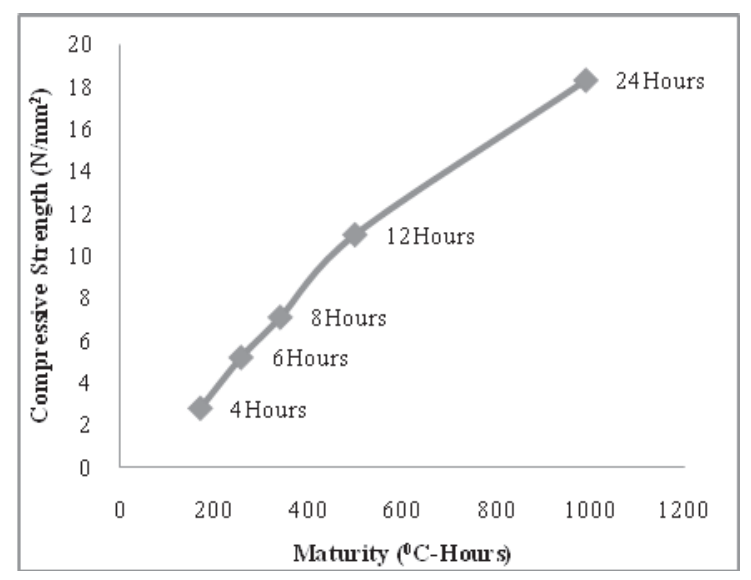

Figure 5 -maturity calibration curve

\section{Applicable Curing Method for Rigid Pavements}

Curing should be properly done to provide required water for the hydration process and to prevent rapid loss of water from the concrete. As the rigid pavements are thin with large surface areas exposed to air compared with the volume of concrete, proper curing method is particularly important. Minimizing evaporation also helps to control plastic shrinkage cracks in concrete at early age.

Sprinkling of water was adopted in this study for curing. But it is impractical to cure with the sprinkle method after allowing traffic, as frequent curing activities disturb the traffic flow. If the surface can be covered with wet jute mats, burlaps or sacks, the rapid evaporation of water from the concrete surface can be minimized (especially in hot weather concreting). Because jute mats can retain water and minimise heat transfer, the frequency of sprinkling water to the rigid pavement can be minimised. Therefore, the curing of rigid pavement should be performed with minimum disturbances to the traffic. However, finding an effective curing method was not focused in this study.

\section{Cost Saving of High Early Strength Concrete}

Cost analysis was performed to estimate the life cycle cost of rigid pavement constructed with typical concrete and high early strength concrete. Comprehensive cost analysis was performed taking into account the initial cost, maintenance cost and user cost. A medium density traffic load with 6000 vehicles per day (vpd) was considered in the analysis. Analysis showed that there is a $26 \%$ saving with high early strength concrete. Cost analysis is illustrated in the appendix. Suggested cost analysis can be applied for any road construction activity

\section{Conclusion}

According to the characteristics of strength gain with $\mathrm{CaCl}_{2}$, three percent $(3 \%)$ of $\mathrm{CaCl}_{2}$ has gained more than $11 \mathrm{MPa}(1600 \mathrm{psi})$ within 12 hours. The proposed mix provided the sufficient workability and setting time was adequate for placing concrete. Early stage temperature development was insignificant due to addition of $3 \% \mathrm{CaCl}_{2}$ and no shrinkage cracks were observed in the slab. Maturity test has proven the strength gain under the field conditions. Therefore, with the use of proposed mix proportion, traffic can be allowed after 12 hours.

Life cycle cost analysis was performed to find the cost effectiveness of the high early strength concrete. Analysis showed that there is a $26 \%$ saving in using high early strength concrete for 
moderately traffic roads. Cost saving is mainly due to minimizing user delay cost.

\section{APPENDIX (COST ANALYSIS)}

\section{Net Present Value (NPV)}

Net Present Value technique explicitly recognizes the time value of money. The initial cost takes place during the year zero. The annual cost from the year zero to ' $n$ ' must be discounted to find the zero year value of such annual cost. The following equation is used to estimate the present worth of each annual cost.

$$
\begin{aligned}
& P=\frac{A_{1}}{1+i}+\frac{A_{2}}{(1+i)^{2}}+\frac{A_{3}}{(1+i)^{3}}+\ldots \ldots \ldots+\frac{A_{n}}{(1+i)^{n}} \\
& P=\sum \frac{A_{i}}{(1+i)^{i}}
\end{aligned}
$$

$$
\begin{array}{ll}
\text { Where } & A_{i}-\text { cost in } i^{\text {th }} \text { year } \\
& \mathrm{i}-\text { Discounting factor } \\
& \mathrm{P}-\text { Life cycle cost. }
\end{array}
$$

\section{Determination of discounting factor}

Value of money changes with the effects of inflation and interest rate. Based on several economic parameters the discounting rate should be estimated. Discounting factor changes with the inflation and interest rate.

The mathematical relationship for discounting factor (i) can be given as below

$$
\begin{aligned}
& i=\frac{(1+e)}{(1+d)}-1 \\
& \text { Where i-discount rate } \\
& \text { e - Interest rate } \\
& \mathrm{d} \text { - Inflation rate }
\end{aligned}
$$

Interest rate $-13.40 \%$ (Central Bank, Sri Lanka, March, 2008)

Inflation (CCIP) - 23.8\% (Central Bank, Sri Lanka, March, 2008)

Hence discounting rate $=i=\frac{(1+0.134)}{(1+0.238)}-1=$ $8.4 \%$

\section{General cost components}

There are two major cost components associated with road construction; (1) Initial cost and (2) Maintenance cost

\section{Initial cost}

Initial cost can basically be divided into three major parts, i.e. land acquisition cost, design and professional fee and construction cost.

\section{Maintenance cost}

Maintenance cost includes the costs of maintenance of the road surface.

\section{Estimation of cost of rigid pavements}

Estimation of maintenance cost of rigid pavements was performed for a traffic volume of $6000 \mathrm{vpd}$. Table A1 gives the cost of materials and laying of concrete per $\mathrm{m}^{3}$.

Table A1 - Unit cost estimation

\begin{tabular}{|l|l|l|}
\hline Resource & $\begin{array}{l}\text { Amount } \\
\left(\text { per } \mathbf{1 m}^{3} \text { ) }\right.\end{array}$ & Cost \\
\hline Cement & $417 \mathrm{~kg}$ & Rs. $6130 /=$ \\
\hline Sand & $692 \mathrm{~kg}$ & Rs. $2726 /=$ \\
\hline Metal & $1024 \mathrm{~kg}$ & Rs. $3035 /=$ \\
\hline CaCl 2 & $12.5 \mathrm{~kg}$ & Rs. $400 /=$ \\
\hline Labour \& equipment & & Rs. $2000 /=$ \\
\hline \multicolumn{2}{|l|}{ Total amount per $1 \mathrm{~m}^{3}$} & Rs. $14291 /=$ \\
\hline
\end{tabular}

Concrete thickness $-150 \mathrm{~mm}$

Assuming that, in one working day, $500 \mathrm{~m}$ of $3.0 \mathrm{~m}$ wide and $150 \mathrm{~mm}$ thick pavement can be constructed. The initial cost can be calculated as follows.

Initial cost $=14,291 \times 500 \times 3.0 \times 0.15$

$$
=\text { Rs. } 3,215,475 /=
$$

\section{Joint construction cost}

Joint construction cost $=$ Rs.250/= per linear meter Joint spacing $=3.0 \mathrm{~m}$

Total linear joint length for $500 \mathrm{~m}$ length $3 \mathrm{~m}$ width section $=498 \mathrm{~m}$

Joint construction cost $=$ Rs.249,500/= (using a sawing machine as recommended in the specification SSCM 2008)

User delay cost

Estimation of value of time for transport user groups [13].

Table A2 -Value of time

\begin{tabular}{|l|l|l|l|l|}
\hline $\begin{array}{l}\text { User } \\
\text { group }\end{array}$ & $\begin{array}{l}\text { Value of } \\
\text { time, } \\
1999 \\
\text { Rs } / \mathrm{hr})\end{array}$ & $\begin{array}{l}\text { Value of } \\
\text { time, } \\
2008 \\
\text { Rs } / \mathrm{hr})\end{array}$ & $\begin{array}{l}\text { Vehicle } \\
\text { occupa } \\
\text { ncy }\end{array}$ & $\begin{array}{l}\text { Value of } \\
\text { time } \\
(2008 \\
\text { Rs/hr) }\end{array}$ \\
\hline Car & 106.50 & 131.85 & 2.2 & 290.07 \\
\hline Van & 48.44 & 59.97 & 3.8 & 227.89 \\
\hline M.cycle & 19.22 & 23.80 & 1.35 & 32.13 \\
\hline $\begin{array}{l}\text { Public } \\
\text { transport }\end{array}$ & 11.62 & 14.38 & 50 & 719.00 \\
\hline
\end{tabular}
database, 2002) is 26, 13, 10 and 5 percent for cars, motorcycles, van and public transport respectively. For a traffic volume of 3000vpd

User delay cost per day $=3000 \mathrm{x} \quad(0.26 \times 290.07+$

$0.13 \times 227.89+0.10 \times 32.13+0.05 \times 71$ )

= Rs. 335,421/Day

For a traffic volume of 6000vpd

User delay cost per day $=6000 \times(0.26 \times 290.07+$

$0.13 \times 227.89+0.10 \times 32.13+0.05 \times 71)$

$=$ Rs. $670,842 /$ Day 
Calculation is for $r$ a two lane highway

Initial Cost for Option 1 (12 hours closure)

Based on current research study, time required to gain strength after placing concrete $=12$ Hours

Therefor total duration of road closure (assuming 12 hours for construction) $\quad=24$ hours

User delay cost (For a traffic volume of 6000vpd) per one lane for 24 Hours $=$ Rs. $335,421 /=$

Initial cost + Joint construction cost + user delay cost $=$ Rs.3800396/=

Initial cost per $1 \mathrm{~m}^{2}$ of concrete pavement

$=$ Rs. $2,757 /=$

Initial cost for option II ( 7 days road closure)

For a 7 day road closure: (As per specification, 24 hours compressive strength should exceed 20.7 MPa to allow traffic)

Initial cost + Joint construction cost + user delay cost $=$ Rs.5,812,922/=

Initial cost per $1 \mathrm{~m}^{2}$ of concrete pavement

$=$ Rs. $3,876 /=$

General Maintenance cost (Identical for both options)

General maintenance cost $=45000 \times 0.5$

$=$ Rs. $22,500 /=$

General maintenance cost per $1 \mathrm{~m}^{2}=$ Rs.15/=

Assumption - 1\% of slab replacement in every 10 years

Slab replacement cost $=$ (Initial cost + Joint construction cost) $\times 1 \%=$ Rs. $23 /=$

\section{Option 1 - Cost estimation (percent value)}

Initial cost $=$ Rs. $2,757 /=$ per $\mathrm{m}^{2}$

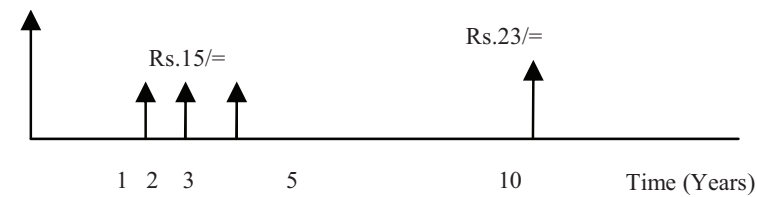

By considering 20 years Duration, for $\mathrm{i}=8.4 \%$ life cycle cost is given below.

$$
\begin{gathered}
P=2,757+\frac{15}{(1+0,084)^{1}}+\frac{15}{(1+0.084)^{2}}+\cdots+\frac{23}{(1+0,084)^{5}}+\cdots \\
\mathbf{P}=\text { Rs.3, 178/= }
\end{gathered}
$$

Cost of $1 \mathrm{~m}^{2}$ of concrete pavement (150mm thick) for a design life of 20 Years $=$ Rs.3, 178/=

\section{Option 2 - Cost estimation (percent value)}

Initial cost $=$ Rs. $3,876 /=$ per $\mathrm{m}^{2}$

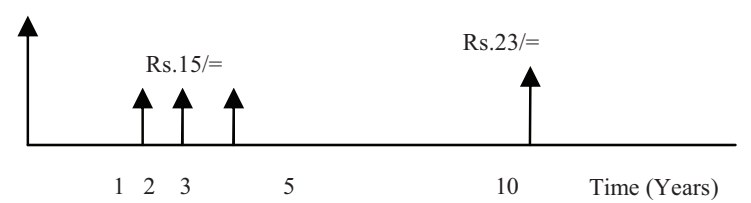

By considering 20Years Duration, for $\mathrm{i}=8.4 \%$, Life cycle cost

$P=2,757+\frac{15}{(1+0.084)^{2}}+\frac{15}{(1+0.084)^{2}}+\cdots+\frac{23}{(1+0.084)^{3}}=\cdots$

$$
\begin{aligned}
& P=2,7=3,876+\frac{15}{+0.084)^{2}}+\frac{15}{(-+0.084)^{2}}+\cdots+\frac{23}{(1+0.084)^{5}}+\cdots \\
& P=R s .4,297 /=
\end{aligned}
$$

Cost of $1 \mathrm{~m}^{2}$ of concrete pavement (150mm thick) for a design life of 20 Years = Rs.4, 297/=

Cost saving of high early strength concrete

$=\frac{4,297-3178}{4297} \times 100$

$=26.0 \%$

\section{References}

1. State-of-the-Art Report, FHWA Special Project 201, Report FHWASA- 94-080, Accelerated Rigid Paving Techniques, Federal Highway Administration, Washington, D.C., 1994.

2. Technical Committee Document ACI 325.11R, Accelerated Techniques for Concrete Paving, Committee 325, American Concrete Institute, Farmington Hills, Mich., 2001.

3. American Association of State Highway and Transportation Officials (AASHTO), Guide for Design of Pavement Structures, Washington, DC. ,1993.

4. California Department of Transportation, CalTrans, Slab Replacement Guidelines, California Department of Transportation, Publication and Distribution Unit, 1900 Royal Oaks Drive, Sacramento, CA, 2004.

5. Crawford, G. I., Guide to Nondestructive Testing of Concrete. FHWASA-97-105, .Federal Highway Administration, Washington, DC, 1997.

6. Technical Committee Document ACI 224.1R-93, Causes, Evaluation, and Repair of Cracks in Concrete Structures, Committee 224, American Concrete Institute, Farmington Hills, Mich., 1998. 
7. Florida Department of Transportation (FDOT), Standard Specification for Road and Bridge Construction, FDOT, Maps and Publications, Tallahassee, FL, 2004.

8. Gayani, J.,K.,U., "Determination of Concrete thickness for Rigid Pavements with Recycled Concrete Aggregate for Low Volume Roads in Sri Lanka", University of Moratuwa, Sri Lanka Masters Thesis, 2010.

9. Gerald, F., V., "Early Cracking of Concrete Pavement - Causes and Repairs," presented for the Federal Aviation Administration Airport Technology Transfer Conference, Atlantic city International Airport, NJ, USA,2002.

10. Huang, Y. H., Pavement Analysis and Design, Prentice Hall, Upper Saddle River, New Jersey, 1993, pp 168-207.

11. Kumara, M. W., Tia M., Chung-Lung $\mathrm{Wu}$, and Bouzid Choubane, "Analysis of Composite Pavements under moving and Static Wheel Load from a Heavy-Vehicle Simulator,''Department of Civil \& Coastal Engineering", College of Engineering, University of Florida, Gainesville, FL 2005.

12. Kumara, M. W., "Analysis and Verification of Stresses and Strains and their Relationship to Failure in Concrete Pavements Under Heavy Vehicle Simulator Loading" Ph.D. Dissertation, University of Florida, 2005.

13. Kumarage, A.S.K., "Assessing Public Transport Investment in the Transport Sector", Department of National Planning, Ministry of Finance and Planning, Colombo, Sri Lanka, 2001.

14. Nelson, P. K., "Handbook of Nondestructive and Innovative Testing Equipment for Concrete," Federal Highway Administration, Washington, D.C., 2003.
15. Neville, A.M., and Brooks, J.J., "Concrete Technology", Pearson, ISBN 81-7808-647-6, 2004, pp- 193-202.

16. PCA, "Thickness Design for Concrete Highway and Street Pavements," Skokie, IL, 1984.

17. Ramachandran, V. S., Calcium Chloride in Concrete. Science and Technology. Essex, England: Applied Science Publishers, 1976.

18. Ramachandran, V. S., Accelerators. In Concrete Admixtures handbook: Properties, Science, and Technology, Noyes Publication, Park Ridge, N. J., 1984.

19. Saul, A. G. A., "Principles Underlying the Steam Curing of Concrete at Atmospheric Pressure", Magazine of Concrete Research, Vol. 2, no. 6. Thomas Telford Publishing, London. 1951.

20. Shoukry, S.N., William, G.W., and Sirinivasan, S., "Analysis of Mid- Slab Transverse Cracking in Jointed Concrete pavements". The International Journal of Pavements, Vol. 1, No. 3, 2002, pp. 81-94.

21. Teychenne, D.C., Franklin, R.E. and Emtroy, H. C., Design of Normal Concrete Mixes, Building Research Establishment, 2nd edition, 1997 
